\title{
Valuing reductions in water extractions from groundwater basins with benefit transfer: The Great Artesian Basin in Australia
}

\section{J. Rolfe ${ }^{1}$}

Received 29 July 2009; revised 20 January 2010; accepted 31 March 2010; published 29 June 2010.

[1] The management of groundwater to generate net community benefits is challenging because of the complexity of impacts that can be involved, the varying interests of different stakeholder groups, time lags between changes in extraction rates and aquifer levels, and the level of technical and scientific uncertainty. In an economic framework, decisions about conserving groundwater reserves by limiting extraction rates should be made by comparing the benefits of conservation activities with the associated costs. However, limited information about benefits and costs makes it difficult to apply a benefit-cost framework to issues of groundwater management. This can be addressed to some extent by sourcing nonmarket values from other studies in a benefit transfer process. In this paper, benefit transfer techniques are applied to an evaluation case study about limiting extractions from the Great Artesian Basin in Australia. The results demonstrate some of the issues with the benefit transfer approach and confirm that the publicly funded bore capping program in Australia has been delivering net benefits to the community.

Citation: Rolfe, J. (2010), Valuing reductions in water extractions from groundwater basins with benefit transfer: The Great Artesian Basin in Australia, Water Resour. Res., 46, W06301, doi:10.1029/2009WR008458.

\section{Introduction}

[2] Justifying a program to limit extractions from a groundwater basin requires an assessment of the benefits and costs to determine if net community benefits are generated [Koundouri, 2004]. A cost-benefit analysis is appropriate for this purpose, and can demonstrate how positive and negative impacts often accrue to different groups. Benefits of a control program can include benefits of achieving a sustainable yield in the longer term, and the maintenance of environmental assets associated with groundwater, together with any cultural and social values. The costs of a control program will normally include any losses in productivity from restricting water to current users, subsequent social costs that may be generated, as well as associated administration and management costs.

[3] The application of economic analysis to management of groundwater systems is difficult for a number of reasons [Koundouri, 2004]. Groundwater flows are typically very complex to model, there are long time lags between inflows and outflows (as well as between changes in extraction rates and the stock of groundwater), and there are high levels of technical and scientific uncertainty. The analysis is further complicated by the difficulties of identifying the different impacts, and then, in a cost-benefit framework, valuing the impacts so that they can be compared. Even when an extended benefit-cost analysis is undertaken, the social benefits of controlling groundwater extraction are usually

\footnotetext{
${ }^{1}$ Centre for Environmental Management, Central Queensland University, Rockhampton, Queensland, Australia.

Copyright 2010 by the American Geophysical Union. 0043-1397/10/2009WR008458
}

too low to justify intervention measures [Gisser and Sanchez, 1980; Koundouri, 2004].

[4] These complexities can be illustrated with the analysis of control programs for the Great Artesian Basin (GAB) in Australia. The GAB is one of Australia's most significant and well known natural resources, being an underground water "reservoir" underlying approximately one fifth of the continent [Great Artesian Basin Consultative Committee $(G A B C C), 1998]$. The GAB is significant to Australia in a number of ways, contributing to the economies of pastoral (extensive beef and sheep grazing), tourism and mining industries, providing water to communities and townships, supporting important environmental assets, and underpinning aboriginal cultural heritage and Australian settlement heritage legacies. The groundwater reserves in the $\mathrm{GAB}$ have been accessed by European settlers since the 1880s, with significant subsequent development for pastoral, infrastructure and mining purposes. The development has not been without its environmental costs, with some of the outcomes including increased weeds and pests and biodiversity losses from reduced flows at natural springs. Concerns about the environmental impacts and the ongoing viability of extractions led to the introduction of a coordinated bore capping program in 1999, called the Great Artesian Basin Sustainability Initiative (GABSI), with funding requirements shared between government and private property owners.

[5] Evaluation of management programs to limit groundwater extraction rates and the GAB and the public investment involved is hampered by several gaps in knowledge about the different benefits and costs involved. Financial costs are relatively easy to assess as the contributions made by the Australian government, state governments and landholders are reasonably transparent. There are limited production impacts of reducing rates of groundwater extraction, and any 
negative social impacts on landholders are expected to be minor. The major information gaps relate to the off-farm benefits that may be generated from the GABSI, particularly those relating to nonfinancial social and environmental impacts.

[6] There are a number of nonmarket valuation techniques available to assess values for impacts that are not directly reflected in market prices [Bateman et al., 2002]. However, there are very few studies which are focused on valuing groundwater recharge [e.g., Acharya and Barbier, 2002; Cutter, 2007] or the impacts of better groundwater management [e.g., Hellegers et al., 2007]. An alternative to conducting primary nonmarket valuation studies for a benefitcost analysis is to transfer values from other similar studies for different components [Brookshire and Neill, 1992; Brouwer, 2000; Rolfe and Bennett, 2006]. The use of benefit transfer in the evaluation of groundwater management options is limited, partly because of a number of challenges in performing this type of analysis.

[7] In this paper the review and transfer of values from other nonmarket valuation studies in related areas is used to demonstrate the potential application of benefit-cost analysis to groundwater management issues. A case study application to the bore capping program in the Great Artesian Basin in Australia provides a demonstration of how benefit transfer techniques can be used to assess the benefits of improved management of water resources. The paper is structured in several key parts. First, an overview of costbenefit analysis and the use of benefit transfer to help in applications is provided in section 2. This is followed by a review of the GAB case study in section 3, followed by a categorization and identification of the benefits of the GABSI in section 4. The benefit transfer exercise and case study evaluation is provided in section 5, followed by conclusions in section 6 .

\section{Benefit-Cost Analysis and Benefit Transfer of Nonmarket Values}

[8] Benefit-cost analysis is the standard economic framework used to evaluate alternative resource uses and policy choices in terms of overall gains or losses to society. It has sound theoretical roots in welfare analysis, and has been widely used for more than 40 years. The key steps in the application of the technique include the identification of relevant impacts and subsequent valuation so that impacts can be compared in a standard metric. A range of nonmarket valuation techniques have been developed to assess impacts where values are not directly available from market transactions. These include revealed preference techniques, particularly the hedonic pricing and travel cost methods, and stated preference techniques, which include the contingent valuation and choice modeling techniques. The revealed preference techniques are capable of estimating use values (amenity and recreation values, respectively), while the stated preference techniques are commonly used to estimate nonuse values such as those associated with protecting biodiversity.

[9] There are two approaches to estimating nonmarket values for a topic of interest. The first is to conduct a primary study that includes data collection, statistical analysis and interpretation stages, employing relevant revealed preference and stated preference techniques. Primary studies can be technically complex, expensive and time consuming [Rolfe and Bennett, 2006]. These factors, coupled with the small pool of skilled researchers and analysts, help to explain why the number of nonmarket valuation studies internationally and in Australia remains limited.

[10] The second broad approach is to transfer environmental values from one or more existing case studies to a target site of interest, a pragmatic process known as benefit transfer [Brookshire and Neill, 1992; Brouwer, 2000; Rolfe and Bennett, 2006]. In applications of benefit transfer, nonmarket values gained from a "source" study can be used in some way to predict economic values at a "target" site [Bateman et al., 2002; Rolfe and Bennett, 2006]. The process typically involves transferring and adjusting values across time, space, populations, and sometimes from one type of environmental asset to another [Brouwer, 2006; Rolfe, 2006]. Benefit transfer is only possible in situations where there are existing studies that relate to the target issue of interest, the existing studies are technically accurate, and the transfer process will not generate unacceptable biases.

[11] Most applications of benefit transfer are opportunistic, involving a search for suitable source studies followed by transfer with some potential adjustment process [Rolfe and Windle, 2008]. This opportunistic approach to benefit transfer is still restricted for a number of reasons, including the limited number of available studies, inconsistencies in the way that data has been collected and modeled, and the brevity of reporting in many academic publications [Rolfe and Windle, 2008]. Many studies are conducted and reported for specific purposes, with little consideration for subsequent use in benefit transfer applications. This limits the potential for benefit transfer, although there has been a great deal of effort by practitioners in the 1990s and early 2000 s to understand where sources of bias in the benefit transfer process might be generated, and to develop more accurate ways of performing nonmarket valuation studies and the benefit transfer process [Wilson and Hoehn, 2006; Rolfe and Windle, 2008].

[12] The development of stated preference techniques such as choice modeling have facilitated the use of benefit transfer values and functions because choice modeling allows the expression of environmental values as a function of a number of site, population and other characteristics [Rolfe, 2006]. A choice modeling experiment can be designed in a way so that key elements desired in a benefit transfer function are included in the choice sets as attributes or labels. The choices made by respondents from a survey population thus help to develop a benefit transfer function that can be "mapped" across to a range of potential policy situations. As choice modeling enables value estimation for nonmarket benefits such as environmental protection and community health, it can generate key results for benefitcost analysis.

\section{Great Artesian Basin}

[13] The GAB (Figure 1) underlies 1.7 million $\mathrm{km}^{2}$ of largely arid and semiarid regions in Australia, underlying the states of Queensland, New South Wales and South Australia [GABCC, 1998]. Most water enters the basin in recharge zones along the western side of the Great Dividing Range, on the eastern margin of the basin. The groundwater then flows mainly southwest and westward at a rate of 


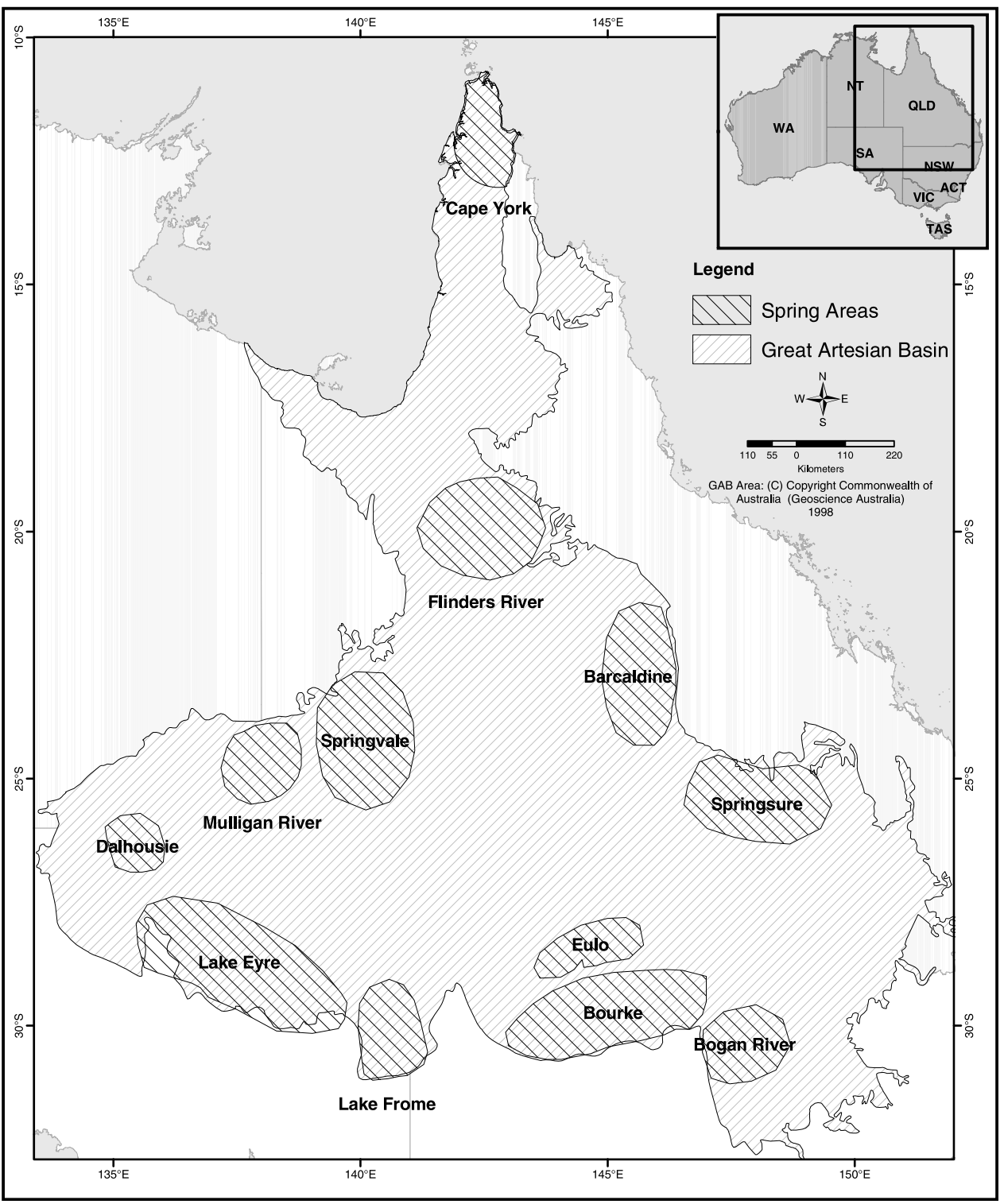

Figure 1. Great Artesian Basin.

between 1 to $5 \mathrm{~m} \mathrm{yr}^{-1}$ [Ponder, 2004], with the age of some groundwater estimated at close to 2 million years [ $G A B C C$, 1998]. The geology and associated hydrogeology of the basin creates variation in the artesian aquifers and associated surface features across the basin.

[14] Key environmental and cultural heritage benefits of the GAB are provided by artesian springs, where water moving through the aquifer discharges to the surface through faults in the strata or exposed parts of the aquifer. Before the $1880 \mathrm{~s}$, there were more than 3000 springs in about 600 groups, including thirteen major complexes [GABCC, 1998; Ponder, 2004]. The most notable occur along the southwestern arc of the basin in South Australia from Marree to north of Oodnadatta, including the Dalhousie springs in the Witjira National Park. Some springs are notable as mound springs, where accumulated sediments and carbonate spring deposits over many thousands of years have created small mesas up to $40 \mathrm{~m}$ higher than the surrounding landscape [GABCC, 1998]. Total discharge from the GAB, excluding the Cape York group, is estimated at
$50,000 \mathrm{ML} \mathrm{yr}^{-1}$, with the Dalhousie group accounting for about $40 \%$ of discharge [GABCC, 1998].

[15] Many artesian springs occur on the western side of the GAB in arid regions where they provide important biological refuges that are rich in endemic flora and fauna [Ponder, 1986; Noble et al., 1998; Ponder, 2004; Fensham and Fairfax, 2003]. These include fish such as the Elizabeth Springs goby (Chlamydogobious micropterus) and the Edgbaston goby (Chlamydogobious spp.), and a number of plants. There is a distinctive fauna associated with each major spring group [Ponder, 1986, 2004]. Historically, and currently, the springs are an important part of aboriginal cultural heritage, and although they were not permanently occupied, usage may date back 30,000 years [ $G A B C C$, 1998].

[16] European access to groundwater in the GAB began from the $1880 \mathrm{~s}$, and bores were extensively developed to support the pastoral sector, and in more recent times townships and mining. $G A B C C[1998]$ reported about 3,000 free-flowing artesian bores and 35,000 subartesian (non- 
Table 1. Summary of Water Extraction in the GAB ${ }^{a}$

\begin{tabular}{lccc}
\hline \multicolumn{1}{c}{ Industry } & Pre-European & $\begin{array}{c}\text { Estimated Water } \\
\text { Extraction in } \\
1998\left(\mathrm{ML} \mathrm{yr}^{-1}\right)\end{array}$ & $\begin{array}{c}\text { Predicted Water } \\
\text { Extraction in } \\
2005\left(\mathrm{ML} \mathrm{yr}^{-1}\right)\end{array}$ \\
\hline Pastoral & 0 & 500,000 & 400,000 \\
Mining & 0 & 11,000 & 35,000 \\
Petroleum & 0 & 20,000 & $20,000 ?$ \\
Town supply & 0 & 20,000 & 20,000 \\
Tourism & 0 & minimal & 6,000 \\
Irrigation & 0 & 8,000 & 35,000 \\
Industrial & 0 & 6,000 & 9,000 \\
Total extraction & 0 & 565,000 & 565,000 \\
Natural discharge & 82,000 & 50,000 & not known \\
\hline
\end{tabular}

${ }^{\text {a }}$ Source: GABCC [1998].

flowing) bores were tapping the aquifer, drawing about $570,000 \mathrm{ML} \mathrm{yr}^{-1}$ in the late 1990 s. The pastoral industry accounted for approximately $88 \%$ of use (Table 1), of which as much as $90 \%$ was lost in evaporation and seepage. This occurs through the widespread use of open bore drains to distribute water rather than more efficient reticulation systems involving piping and troughs [Pegler et al., 2002]. Growth in mining, irrigation, petroleum and tourism industries is expected to increase demands for groundwater in the future (Table 1).

[17] The access to groundwater in the GAB has reduced pressure and flow across many parts of the basin. There is approximately one million ML of water entering and exiting the GAB system each year [GABCC, 1998]. The maximum groundwater extraction was estimated to be $750,000 \mathrm{ML}$ in 1915 , and has since fallen by approximately $25 \%$ [ $G A B C C$, 1998], with individual head levels in bores falling up to $80 \mathrm{~m}$ over this time period [Ponder, 2004]. This has caused a substantial reduction in water access to artesian springs, with approximately one third of all springs, including the Flinders River "supergroup," disappearing since the 1880s [Ponder, 2004]. Total discharge through artesian springs has reduced by nearly $40 \%$ from an estimated $82,000 \mathrm{ML} / \mathrm{yr}^{-1}$ predevelopment to $50,000 \mathrm{ML} \mathrm{yr}^{-1}$, with subsequent losses of biodiversity at spring sites [GABCC, 1998].

[18] Extraction from the GAB has generated a number of other losses apart from the biodiversity around artesian springs. There have been impacts on water access, with approximately 1,500 bores ceasing to flow, and the lowering of water tables increasing pumping costs. Reduced water flows at artesian springs have the potential to impact on tourism, now one of the major economic activities in the GAB area. Webster [1995] suggested that at least 10,000 people per annum were visiting the Dalhousie Springs complex in Witjiri National Park, with many of them staying for several days. By comparison, there are approximately 900,000 visitors annually to the Coorong at the mouth of the Murray River, also in South Australia [Dyack et al., 2007]. Major spring areas are also important in terms of cultural heritage for aboriginal groups and for links to early exploration and European settlement history [Webster, 1995].

[19] The extraction of water from the GAB may also be associated with greenhouse gas emissions, as dissolved gas concentrations of $\mathrm{CO}_{2}$ (carbon dioxide), $\mathrm{CH}_{4}$ (methane) and some hydrocarbons can be released when the groundwater is brought to the surface. Pallasser and Alder [2001] estimate that $334,000 \mathrm{t}$ of carbon dioxide equivalents $\left(\mathrm{CO}_{2}-\mathrm{e}\right)$ are released annually from the GAB through both bores and natural springs, and that a $25 \%$ reduction in water extractions should decrease total emissions of carbon dioxide

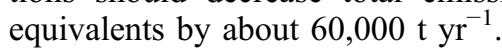

[20] Extensive open drains to distribute bore water have also contributed to environmental losses by facilitating the spread of weeds and feral animals, contributing to salinization, increasing grazing pressure and allowing more access by predators to remote areas. The combination of different pressures in rangeland areas, including losses of artesian springs and extensive use of open bore drains among other factors such as grazing pressures and feral pests, has contributed to significant impacts on biodiversity [ $G A B C C$, 1998], with some medium-sized mammals becoming extinct, displacement of ground-dwelling birds, changed distribution of invertebrates, and extinction of some plant species and vulnerability of others.

[21] Concerns about the health of the GAB led the Australian and state governments to introduce the GABSI in 1999. Expenditure by commonwealth and state governments (in 2007 A\$) was a total of \$64.4 million in phase 1 (19992004), and \$45.6 million in the first three years of phase 2 (2004-2007). Results of the GABSI program show that between 1999 and 2007, approximately 24\% of bores have been capped, $32 \%$ of open bore drains have been removed, and there has been a $25.6 \%$ reduction in annual water extraction. The estimated annual reduction in water extractions was 98,075 ML in phase 1, and 46,474 ML in phase 2.

[22] However, there is no information about whether the investment in the program has generated net community benefits. Benefit-cost analysis provides an appropriate framework to perform an evaluation. To achieve this, it is necessary to identify and value the benefits generated from the program, and then compare them to the costs incurred.

\section{Identifying the Benefits of the GABSI}

[23] To assess the overall value of a program such as the GABSI, values for the additional benefits need to be estimated and compared to the public investment made. For the evaluation process to be comprehensive, it is important to include the assessment of values for the off-farm benefits, as these are likely to be the critical values that justify public investment. Advances in nonmarket valuation techniques make it possible to quantify in monetary terms the relevant nonfinancial impacts to provide a complete assessment of the program. A key stage in the analysis of nonmarket values is to categorize the types of benefits that might be associated with the Great Artesian Basin in use, indirect use and nonuse categories. A summary of these potential values is provided in Figure 2.

[24] A typology of the different impacts expected from the GABSI is provided in Table 2, and include both on-farm and off-farm impacts [Hassall and Associates, 2003]. The on-farm benefits are generally private benefits accruing to landholders [Pegler et al., 2002]. The off-farm benefits are largely public, accruing to different groups in society, although recreation benefits and tourism benefits are better classified as private benefits occurring off farm. It is notable in this case study that reductions in groundwater extractions have little impact on current production levels, and hence private income. This sets the GAB apart from many inter- 
Total Economic Value

Use Values

Non-use values

\section{$\Gamma$

Direct Use
value

\section{Outputs \& services that can be consumed directly}

\section{Extractive:} water for regional communities, pastoral and mining Non-extractive: Tourism and recreation, aesthetic

Functional
benefits enjoyed
indirectly
Positive: Research
and education,
indirect support for
regional
communities
Negative:
Greenhouse gas
emissions
released with
water extraction

Indirect Use Value

\section{Option \\ Value}

\section{Quasi-option Value}

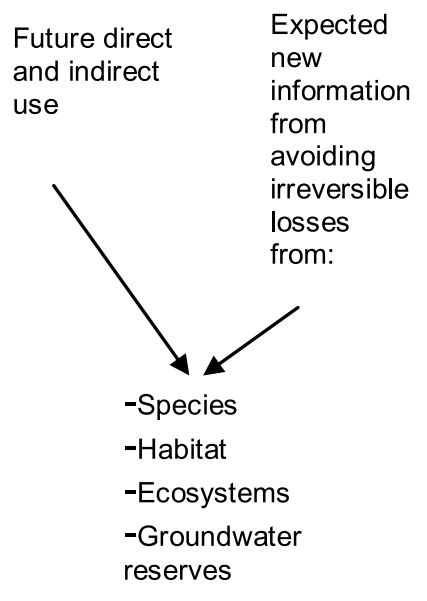

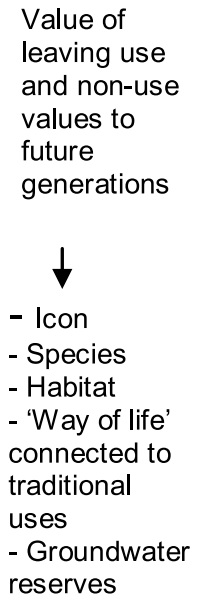

\section{Existence Value}

Figure 2. Total economic value for the Great Artesian Basin.

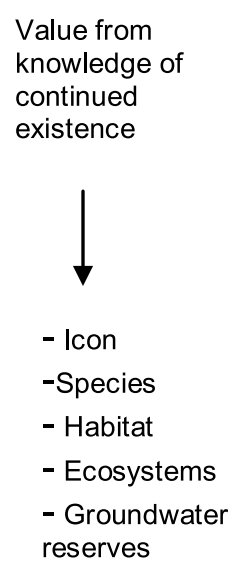

national case studies where high private costs of reducing groundwater extractions tend to outweigh the social benefits of control [Koundouri, 2004].

[25] The on-farm benefits of the bore capping program are limited because of the low productivity of the pastoral land and the marginal impacts on productivity [Pegler et al., 2002]. The private benefits are not large enough by themselves to stimulate private conservation of the groundwater resource. It is the off-farm benefits that are relevant to the justification of public funding for the GABSI. The key offfarm benefits of improving the management of the GAB appear to be as follows.

[26] 1. Conservation will maintain recreation and tourism opportunities, as visitors to the assets of the GAB would be affected by the loss or degradation of those assets. Evidence of the impact could be expected through both a reduction in the number of visitors and a reduction in the value of each visit.

[27] 2. Conservation will increase ecosystem and biodiversity protection by maintaining the health of artesian springs and associated wetlands and biodiversity, particularly those involving unique artesian springs and endemic species.

[28] 3. Land degradation will be reduced through conservation activities. Better management can help to reduce excessive grazing pressure in specific areas, while the elimination of open bore drains can reduce the spread of weeds and pests.

[29] 4. Iconic values may be enhanced by maintaining groundwater reserves. The GAB may have some level of iconic status where there is an inherent value to people beyond the existence value for associated biodiversity. People may value the continued existence and good condition of the asset, as well as valuing the option to potentially use the water reserves for different purposes in the future.

[30] 5. Conservation will help to protect cultural heritage, as many artesian springs form an integral part of cultural heritage for aboriginal people.

[31] 6. Conservation will lead to reductions in greenhouse gas emissions, as each $1 \mathrm{ML}$ reduction in groundwater

Table 2. Summary of Impacts From the GABSI

\begin{tabular}{lll}
\hline & Benefits of Bore Capping and Piping & Cost of Bore Capping and Piping \\
\hline On farm & $\begin{array}{l}\text { Extended life of bores; reduction in the operation and maintenance expenses } \\
\text { association with open drains; management saving associated with mustering }\end{array}$ & $\begin{array}{c}\text { Initial landholder expenditure on capping, } \\
\text { piping and troughs; management changes }\end{array}$ \\
stock; better control of weeds and feral animals & Protection of recreation benefits; protection of biodiversity, including better \\
& control of weeds and feral animals; maintaining groundwater reserves; & Initial Australian and state government \\
& existence value of landscape and ecosystem; reducing greenhouse gas \\
& emissions; protecting aboriginal cultural heritage & expenditure on capping and piping
\end{tabular}


extraction can reduce associated greenhouse emissions by approximately $0.54 \mathrm{t}$ of carbon dioxide equivalents [Pallasser and Alder, 2001].

\section{Identification and Transfer of Values}

[32] Because no studies are available that directly assess the off-farm benefits of GABSI, a benefit transfer process is reported in this paper to provide some assessment of the relevant benefits. A key stage in benefit transfer is to review available literature and identify suitable studies where transfer might take place. Any transfer process has to take account of the issues involved in an accurate transfer process so that undesirable biases are not generated in the analysis [Rolfe and Bennett, 2006].

[33] The first stage in the application of a benefit transfer exercise is to identify suitable nonmarket valuation studies relevant to the key off-farm benefits that were identified. To minimize the potential for transfer errors across populations in this application, only Australian studies were sourced. To minimize transfer errors across sites, only source studies that had similar regional or water resource contexts were selected. A limited number of source studies were identified.

[34] The second task in a benefit transfer exercise is to extrapolate the relevant transfer value to the case study situation. In many cases this requires two key calculations to be made, sometimes with the use of simplifying assumptions. The first is to determine the rate at which the value is to be applied (e.g., recreation benefits per day) where there may be different amounts of marginal improvements to consider. The second is to determine the relevant amount of benefits (e.g., recreation days) to be valued.

\subsection{Recreation}

[35] There are two key stages in the estimation of recreation values: the transfer of values from one or more other case studies, and the extrapolation across relevant visitor numbers. Four key sources were identified for the first stage, each focused on values for general tourism activities. Delforce et al. [1986] assessed the recreation value of tourist trips to the Flinders Ranges area in South Australia, using the travel cost method, at $\$ 35.88$ per trip (\$99.84 in 2007 dollars). Rolfe and Prayaga [2007] estimated the recreation value of visitors to three freshwater dams in Queensland using the travel cost method. The Fairbairn Dam in central Queensland is the most relevant because of its inland location and proximity to the Great Artesian Basin. Using the travel cost method, consumer surplus was estimated at $\$ 904$ per trip, or $\$ 105.79 \mathrm{~d}^{-1}$. Dyack et al. [2007] report recreation values for two sections of the Murray River in Victoria and South Australia, using data and count data models with the travel cost method. The consumer surplus for recreation use of the Barmah in Victoria was estimated at $\$ 134$ per adult visitor per day, while the Coorong was valued at $\$ 218$ per adult visitor per day. An average of those four estimates is $\$ 139.41 \mathrm{~d}^{-1}$, which can be transferred to recreation use in the GAB.

[36] The key task in extrapolating values to the GAB is to identify the appropriate level of visitor numbers. The visitors who are most likely to draw recreation benefits directly from it are those people visiting the Dalhousie Springs complex in Witjira National Park on the edge of the Simpson Desert. Webster [1995] estimated 10,000 visitors per annum to that site. Assuming each visitor stays for two nights would generate annual recreational benefits of $\$ 2.79$ million. However, only part of this can be counted as a benefit of GABSI, because only incremental changes are being made to the resource condition. Using the $25.6 \%$ reduction in annual extraction achieved by GABSI as a proxy for estimating marginal improvements, the annual recreation benefits can be estimated at $\$ 714,000$ for reduced water extraction. If net change in annual groundwater inflows and outflows of $14.4 \%$ is used as a proxy for marginal changes, the annual recreation benefits are estimated lower at $\$ 402,000$.

\subsection{Biodiversity Protection}

[37] One study was identified that used choice modeling to assess biodiversity protection values in the Desert Uplands bioregion, which hosts one of the major groups of artesian springs in the $12 \mathrm{GAB}$. Blamey et al. [2000] estimated the annual value of avoiding the loss of each $1 \%$ of unique ecosystems in the region, including those associated with artesian springs, was $\$ 4.79$ per Brisbane household for 15 years (in 2007 dollars). To apply these values, some estimate of the averted loss of the artesian spring ecosystems needs to be made. Approximately one third of artesian springs have disappeared since the maximum water yield was recorded in 1915, a period of approximately 90 years [GABCC, 1998; Ponder, 2004]. At this rate of loss, it could be predicted that a further $11 \%$ of artesian springs in the region would disappear in the next 30 years. A key biodiversity benefit of the bore capping program is that this loss would be averted. If the part worth is extrapolated across the $11 \%$ of potential loss averted for one eleventh of unique ecosystems, over households in Queensland, NSW and South Australia (4.3 million in the 2006 census), and adjusted for the $50 \%$ nonresponse rate in the surveys, the annual preservation value for artesian spring ecosystems is approximately $\$ 10.3$ million $\mathrm{yr}^{-1}$.

[38] If there are additional benefits in protecting endangered species or nonthreatened species then the biodiversity protection values are likely to be higher. For example Blamey et al. [2000] estimated the annual value of avoiding the loss of each endangered species was $\$ 14.83$ per Brisbane household for 15 years (in 2007 dollars). If it is assumed that the GABSI averts the loss of one endangered species, such as the Elizabeth Springs goby or the Edgbaston goby, then the additional benefit across households in Queensland, NSW and South Australia can be estimated at \$5.8 million $\mathrm{yr}^{-1}$. These values may be conservative because they are based on only one unique ecosystem and one endangered species being protected. The bore capping program will also help to reduce land degradation impacts and minimize the spread of weeds and pests, thus contributing to biodiversity protection. This means that values of protecting biodiversity across several spring groups and other associated biodiversity are likely to be higher.

\subsection{Options for Future Use and Reducing Wastage}

[39] An important component of nonuse values are option values to maintain assets into the future so that future choices can be made about their use and preservation. It can be expected that major iconic assets such as the GAB will be associated with option values, particularly when much of the 
Table 3. Summary of Estimated Values of Benefits

\begin{tabular}{|c|c|}
\hline Valuation Issue & Estimated Annual Value \\
\hline Direct use values for recreation and tourism & Between $\$ 0.4$ and $\$ 0.7$ million $\mathrm{yr}^{-1}$ \\
\hline Biodiversity protection values for native biodiversity & $\begin{array}{l}\$ 10.3 \text { million per annum for artesian spring ecosystems and } \$ 5.8{\text { million } \mathrm{yr}^{-1}}^{-1} \text { for one endangered species }\end{array}$ \\
\hline Biodiversity protection values for removal of pests and weeds & Value included in estimates of biodiversity benefits \\
\hline Option values, for both future use and nonuse purposes & 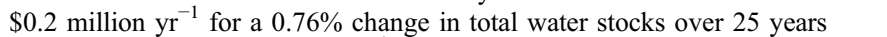 \\
\hline Ecosystem services: reduction in greenhouse gas emissions & $\begin{array}{l}\text { Approximately } \$ 1.14 \text { million } \mathrm{yr}^{-1} \text { in cost reductions to meet emission targets } \\
\text { if reduction in greenhouse emissions is accounted for in national targets } \\
\text { and trading caps }\end{array}$ \\
\hline Cultural heritage protection values & Important, but lack of data does not allow assessment \\
\hline Community protection values & Important, but not related to changing pressure levels \\
\hline
\end{tabular}

water currently extracted is simply being lost to evaporation. One study was identified that used choice modeling to assess option values to maintain water reserves in the Fitzroy river basin in Central Queensland, on the eastern side of the GAB [Rolfe and Windle, 2005]. In that study, the value per household of keeping water in reserve (instead of allocating it to irrigation) was $\$ 1.90$ per $1 \%$ of water reserves for systems that were not highly allocated. This is an annual payment value over 20 years, and would equal to $\$ 18.65$ per household at an $8 \%$ discount rate.

[40] This estimate can be extrapolated to the household populations of Queensland, NSW and South Australia (4.3 million in the 2006 census), and adjusted for the survey response rates $(58.3 \%)$. However, there are some issues in identifying the level of reserves that should be used, as there are differences between the source study and the target application. First, there are significant variations in framing between maintaining water flows in a river basin and maintaining groundwater reserves, particularly when the biodiversity benefits of riparian systems in river basins are considered. Second, marginal effects would be expected to reduce values for larger percentage changes [Rolfe and Windle, 2005]. Third, the GAB has significant stocks of water as well as annual yields, different to a river system, so issues of allocation may be viewed in very different ways. The reduced extractions represent about $14.4 \%$ of annual groundwater inflows and outflows, but only have a cumulative impact of about $0.041 \%$ on total water reserves over 25 years. If the change in total water reserves is used as the basis for conservative benefit estimation, this generates values of $\$ 0.2$ million $\mathrm{yr}^{-1}$ in community values for maintaining the resource.

\subsection{Reducing Greenhouse Gas Emissions}

[41] Pallasser and Alder [2001] estimate that a 25\% reduction in water extractions should decrease total emissions of carbon dioxide equivalents by about $60,000 \mathrm{t} \mathrm{yr}^{-1}$. In the Australian context, a reduction of emissions through the GABSI may potentially offset emission reductions in other parts of the economy, thus allowing potential costs to reduce emissions to be avoided. Such markets for avoiding greenhouse gas emission reductions are still developing in Australia, with the most defined and recent example of a trade in a future Australian greenhouse emissions scheme completed in January 2008 between AGL and Westpac. The agreement is for AGL to sell 10,000 t worth of greenhouse gases to Westpac on 1 February 2012, for $\$ 19 \mathrm{t}^{-1}$ [Warren, 2008]. This provides some basis for identifying a surrogate market value for the opportunity cost of reducing greenhouse gas emissions, with the caveat that the reduction through the GABSI would need to be accounted for in some form in a national trading scheme. At $\$ 19 \mathrm{t}^{-1}$, this would represent an overall cost reduction to the Australian economy of $\$ 1.14$ million.

\subsection{Other Benefits}

[42] There are two other key groups of benefits that may be important in the assessment of the net benefits of reducing extraction rates. The first are enhancements to aboriginal cultural heritage, where maintaining the artesian springs will also have beneficial impacts for indigenous cultural heritage. Rolfe and Windle [2003] report a choice modeling experiment to value protection of aboriginal cultural heritage sites in the Fitzroy Basin, on the eastern side of the GAB. Values of $\$ 3.40$ per indigenous household were reported for each $1 \%$ improvement in the number of sites that were protected. However, it is difficult to perform a benefit transfer exercise with these data because it is not easy to identify which indigenous households in the relevant states may have values for protection in the GAB.

[43] The second group of other benefits are those associated with maintaining communities in the longer term. However, while these values are significant, it is not clear that falling groundwater levels will drive population losses. While the groundwater provides an important ecosystem service, changing pressure levels will have limited impact on communities apart from increasing pumping and access costs.

\subsection{Summary of Benefits}

[44] The benefit transfer exercises provided in section 5.5 are summarized in Table 3 . The results of the benefit transfer exercise confirm that there are significant off-farm values for the GAB. It appears that the benefits of improving the management of the $\mathrm{GAB}$ are at least as high as $\$ 17.8$ million $\mathrm{yr}^{-1}$ if there are unique values for at least one major group of artesian springs, one endangered species protected and $1 \%$ of groundwater protected, as well as considering the cost savings involved in greenhouse gas emission reductions. These estimates will be higher if there are additional ecological benefits and if the values of the remaining Australian population are considered. This can be compared with an annual investment of $\$ 15.5 \mathrm{M}$ from the Australian and state governments in stage 2 of the GABSI to 
give an initial indication that the off-farm benefits outweigh the costs involved.

\section{Conclusions}

[45] The benefit transfer approach demonstrated in this paper provides a guide to the evaluation of management options for groundwater reserves. Many case studies have similar gaps in information about value estimates. In these cases, the use of benefit transfer methods provides one pathway to the assessment of benefits and costs. There are three key challenges in a benefit transfer exercise. The first is to identify suitable source studies, particularly where population or site differences exist. The second is to identify the appropriate elements for benefit transfer, particularly where benefits may be overlapping or where values may be nonlinear. The third is to extrapolate values to the case study when marginal effects or limited impacts are involved. Recommendations to improve the benefit transfer process include the conduct of more primary studies, particularly on groundwater management issues, and better guidelines and examples for benefit transfer applications [Rolfe, 2006].

[46] The case study reported in this paper demonstrates both the application of a benefit transfer exercise as well as some of the issues involved. As no source studies on valuing groundwater protection in Australia could be found, values for the benefits of improved management had to be estimated separately for different components and then consolidated into an overall estimate of benefit value. The adjustment and extrapolation process varied for each estimate of component value so as to accurately reflect the different impacts involved. Potential limitations of the case study approach include differences between source studies and the GAB, difficulties in identifying the scale of change to be valued, and assumptions of linearity made in extrapolating value estimates.

[47] The case study results demonstrate that there is a range of off-farm benefits generated by the GABSI which accrue to different groups in society. Maintaining and improving the condition of the GAB through the GABSI will contribute to recreation uses and maintain water supply for regional communities, contribute to the reduction of greenhouse gases, and maintain ecological and biodiversity assets, cultural heritage and the options for future use and conservation. The results of this benefit transfer exercise suggest off-farm benefits of improving the management of the GAB are $\$ 17.8$ million $\mathrm{yr}^{-1}$, outweighing the annual program costs of $\$ 15.5$ million $\mathrm{yr}^{-1}$. The control program in Australia is notable in that net community benefits can be identified from restricting groundwater access, as most international studies indicate that production losses outweigh the social benefits of control options [Koundouri, 2004].

[48] Acknowledgments. The research reported in this paper is based on work conducted for the Australian Department of the Environment, Water, Heritage and the Arts. The helpful comments of Jeff Bennett, Marc Carter, Jacqui Goonrey, and Derek White are gratefully acknowledged.

\section{References}

Acharya, G., and E. Barbier (2002), Using domestic water analysis to value groundwater recharge in the Hadejia-Jama'are floodplain, northern Nigeria, Am. J. Agric. Econ., 84(2), 415-426, doi:10.1111/14678276.00307 .
Bateman, I. J., et al. (2002), Economic Valuation With Stated Preference Techniques: A Manual, Edward Elgar, Cheltenham, U. K.

Blamey, R., J. Rolfe, J. Bennett, and M. Morrison (2000), Valuing remnant vegetation in central Queensland using choice modelling, Aust. J. Agric. Resour. Econ., 44, 439-456, doi:10.1111/1467-8489.00119.

Brookshire, D. S., and H. R. Neill (1992), Benefit transfers: Conceptual and empirical issues, Water Resour. Res., 28, 651-655, doi:10.1029/ 91WR02590.

Brouwer, R. (2000), Environmental value transfer: State of the art and future prospects, Ecol. Econ., 32, 137-152, doi:10.1016/S0921-8009 (99)00070-1.

Brouwer, R. (2006), Do stated preference methods stand the test of time? A test of the stability of contingent values and models for health risks when facing an extreme event, Ecol. Econ., 60, 399-406, doi:10.1016/ j.ecolecon.2006.04.001.

Cutter, W. B. (2007), Valuing groundwater recharge in an urban context, Land Econ., 83(2), 234-252.

Delforce, R. J., J. A. Sinden, and M. D. Young (1986), Policy preferences and social economic values to resolve pastoralism-tourism conflicts, Landscape Plann., 12, 387-401, doi:10.1016/0304-3924(86)90004-3.

Dyack, B., J. Rolfe, J. Harvey, D. O'Connell, and N. Abel (2007), Valuing recreation in the Murray: Non-market values at Barmah and the Coorong, Water for a Healthy Country Program, Commonw. Sci. and Ind. Res. Organ., Canberra.

Fensham, R. J., and R. J. Fairfax (2003), Spring wetlands of the Great Artesian Basin, Queensland, Australia, Wetlands Ecol. Manage., 11, 343-362, doi:10.1023/B:WETL.0000005532.95598.e4.

Gisser, M., and D. A. Sanchez (1980), Competition versus optimal control in groundwater pumping, Water Resour. Res., 16, 638-642, doi:10.1029/ WR016i004p00638.

Great Artesian Basin Consultative Committee (GABCC) (1998), Great Artesian Basin Resource Study summary, Canberra.

Hassall and Associates (2003), Review of the Great Artesian Basin Sustainability Initiative (phase 1 mid-term review), Dep. of Environ. and Heritage, Canberra.

Hellegers, P. J., K. Oltmer, E. C. Van Ierland, and L. C. Staalduinen (2007), An economic analysis of shallow groundwater management for nature conservation and agricultural production, J. Environ. Plann. Manage., 44(4), 545-559.

Koundouri, P. (2004), Current issues in the economics of groundwater resource management, J. Econ. Surv., 18(5), 703-740, doi:10.1111/ j.1467-6419.2004.00234.x.

Noble, J. C., M. A. Habermehl, J. James, J. Landsberg, A. C. Langston, and S. R. Morton (1998), Biodiversity implications of water management in the Great Artesian Basin, Rangeland J., 20, 275-300, doi:10.1071/ RJ9980275.

Pallasser, R. J., and D. Alder (2001), Greenhouse gas emissions from the Great Artesian Basin within New South Wales: Potential for reducing the atmospheric carbon budget, in Greenhouse Gas Control Technologies: Proceedings of the Fifth International Conference on Greenhouse Gas Control Technologies, edited by D. J. Williams et al., pp. 691-702, Commonw. Sci. and Ind. Res. Organ., Canberra.

Pegler, L., R. Moore, and D. Bentley (2002), Bore drain replacement in south-west Queensland: Benefits and costs for land managers, Rangeland J., 24, 185-206, doi:10.1071/RJ02010.

Ponder, W. F. (1986), Mound springs of the Great Artesian Basin, in Limnology in Australia, edited by P. De Deckker and W. D. Williams, pp. 403-420, Commonw. Sci. and Ind. Res. Organ., Melbourne, Victoria, Australia.

Ponder, W. F. (2004), Desert springs of the Great Artesian Basin, paper presented at Spring-Fed Wetlands: Important Scientific and Cultural Resources of the Intermountain Region, Desert Res. Inst., Las Vegas, Nev. (Available at http://www.wetlands.dri.edu)

Rolfe, J. (2006), Theoretical issues in using choice modelling data for benefit transfer, in Choice Modelling and the Transfer of Environmental Values, edited by J. Rolfe and J. Bennett, pp. 28-53, Edward Elgar, Cheltenham, U. K.

Rolfe, J. C., and J. W. Bennett (Eds.) (2006), Choice Modelling and the Transfer of Environmental Values, Edward Elgar, Cheltenham, U. K.

Rolfe, J., and P. Prayaga (2007), Estimating values for recreational fishing at freshwater dams in Queensland, Aust. J. Agric. Resour. Econ., 51, 157-174, doi:10.1111/j.1467-8489.2007.00369.x.

Rolfe, J., and J. Windle (2003), Valuing the protection of aboriginal cultural heritage sites, Econ. Rec., 79, S85-S95, doi:10.1111/14754932.00094. 
Rolfe, J., and J. Windle (2005), Valuing options for reserve water in the Fitzroy basin, Aust. J. Agric. Resour. Econ., 49, 91-114, doi:10.1111/ j.1467-8489.2005.00265.x.

Rolfe, J., and J. Windle (2008), Testing for differences in benefit transfer values between state and regional frameworks, Aust. J. Agric. Resour. Econ., 52, 149-168, doi:10.1111/j.1467-8489.2008.00405.x.

Warren, M. (2008), AGL makes first trade in emissions scheme, Australian, 20 May, 2.
Webster, T. (1995), Witjiri, Aust. Geogr., 39, 52-71.

Wilson, M. A., and J. P. Hoehn (2006), Valuing environmental goods and services using benefit transfer: The state-of-the-art and science, Ecol. Econ., 60, 335-342, doi:10.1016/j.ecolecon.2006.08.015.

J. Rolfe, Centre for Environmental Management, Central Queensland University, Rockhampton, Qld 4702, Australia. (j.rolfe@cqu.edu.au) 